\title{
Por uma geografia econômica da esperança
}

\section{Leandro Dias de Oliveira}

\section{(2) OpenEdition \\ Journals}

Edição electrónica

URL: http://journals.openedition.org/espacoeconomia/1792

DOI: 10.4000/espacoeconomia.1792

ISSN: 2317-7837

\section{Editora}

Núcleo de Pesquisa Espaço \& Economia

\section{Refêrencia eletrónica}

Leandro Dias de Oliveira, " Por uma geografia econômica da esperança », Espaço e Economia [Online],

7 | 2015, posto online no dia 09 abril 2016, consultado o 22 setembro 2020. URL : http://

journals.openedition.org/espacoeconomia/1792; DOI : https://doi.org/10.4000/espacoeconomia.

1792

Este documento foi criado de forma automática no dia 22 setembro 2020.

(c) NUPEE 


\title{
Por uma geografia econômica da esperança
}

\author{
Leandro Dias de Oliveira
}

1 David Harvey, em Espaços de Esperança (São Paulo: Edições Loyola, 2004 [2000]), nos instiga a realizar uma geografia da esperança, apostando em nossa capacidade de formular novas utopias verdadeiramente transformadoras. Na qualidade de reais arquitetos de nosso futuro, torna-se preciso fazer recomendações e tomar decisões a partir do conhecimento profundo da realidade. Há que se ter confiança na capacidade de reconstrução do mundo, tornando-o mais justo e igualitário.

2 O que há em comum entre os textos desta edição de Espaço e Economia: Revista Brasileira de Geografia Econômica [Ano 4, n.o 7, Jul.-Dez. 2015] que agora apresentamos é a esperança na construção de um futuro melhor. Seja por aventar as potencialidades das trocas comercias entre a África e as nações denominadas BRICS ou das fronteiras outrora instransponíveis pelo controle do regime soviético; ou ainda por apostar na força do turismo em áreas rurais e do ecoturismo em comunidades tradicionais; da mesma maneira, com a intenção de ir além da sustentabilidade como bandeira ideológica e do desenvolvimento como expressão da pujança econômica, cada texto desta edição traz o signo da esperança com base na ação política.

O primeiro artigo, de nossa autoria, se intitula "A emersão da Região Logístico-Industrial do Extremo Oeste Metropolitano Fluminense: reflexões sobre o processo contemporâneo de reestruturação territorial-produtiva". Trata-se da síntese dos resultados de cerca de cinco anos de pesquisa sobre a borda oeste da região metropolitana do Rio de Janeiro, e apresenta tensionamentos teóricos que envolvem: [i] a atual reabilitação da fábrica como esperança de desenvolvimento em áreas outrora marginalizadas; [ii] a consolidação da ideologia do desenvolvimento sustentável como opção produtiva; [iii] a refundação da empresa em esconderijos espaciais e em plantas que remetem a verdadeiros "bunkers" em meio à guerra urbana; e [iv] o império econômico da capacidade logística em territórios cada vez mais fluidificados.

O segundo artigo, intitulado "Intangible cultural heritage and sustainable development in the Douro Demarcated Region (Northern Portugal): the cases of Cambres and Parada do Bispo", é de 
autoria de Helena Pina, professora da Faculdade de Letras da Universidade do Porto [FLUP-U.PORTO] e referência maior para todos aqueles que se dedicam aos estudos da produção vitivinícola da Região Demarcada do Douro. A partir de Cambres e Parada do Bispo, a autora avalia as potencialidades econômicas do turismo em áreas rurais, destacando o papel estratégico das festas populares e peregrinações no desenvolvimento rural sustentável.

O artigo seguinte é assinado por Nelson Laura Mabucanhane, doutorando de Políticas Públicas e Formação Humana (PPFH) na Universidade do Estado do Rio de Janeiro (UERJ) e docente de Políticas Públicas e Análise de Políticas Públicas no Instituto Superior de Administração Pública em Moçambique, e tem como título "A Nova Era de Cooperação Moçambique - China: Debates, Dilemas, Realidades e Perspectivas de Políticas Institucionais". Em tempos de crise de commodities e desconfiança da real condição da China cumprir os prognósticos e tornar-se a superpotência do Século XXI, Mabucanhane retoma o debate sobre os BRICS [Brasil, Rússia, Índia, China e África do Sul] e dos ganhos das nações africanas - neste caso, Moçambique - com estes países considerados importantíssimos players no cenário global deste século que ainda se inicia.

6 No próximo texto, "Geographic location and contemporary state borders of Bulgaria", Slavi Dimitrov, Professor da Universidade de Veliko Tarnovo "São Cirilo e São Metódio" [Bugária], discute as potencialidades das "fronteiras" búlgaras no tempo presente. Após uma abrangente leitura histórica, Slavi Dimitrov revela a intensificação da cooperação econômica nas fronteiras búlgaras, especialmente com os países limítrofes: Romênia, Sérvia, Macedônia, Grécia e Turquia; trata-se de um importante diálogo com as recentes mudanças territoriais da Bulgária, por intermédio da transição da política econômica pós-Guerra Fria e inserção búlgara na ordem mundial da globalização.

7 A seguir, Jorge Adalberto Aziz da Silva [UFRRJ-Macaé], Beatriz Rohden Becker [PAPESCA] e Rodrigo Lemes Martins [UFRRJ-Macaé] assinam "Macaé e a sustentabilidade do projeto de 'Capital Nacional do Petróleo"', um esforço de análise factual acerca do modelo de desenvolvimento sustentável. A cidade de Macaé, sede econômica nacional da extração da commodity que refundou o modelo de produção de mercadorias no Século XX, é aqui o objeto empírico: irrigada pelos aportes financeiros da economia petrolífera em sua forma urbano-regional, Macaé é um típico caso de difícil construção da sustentabilidade em múltiplas esferas: política, econômica, social, cultural e, particularmente, ambiental.

8 Fechando a seção de artigos, "O processo de reestruturação territorial-produtiva na cidade de Itaguaí - RJ", de Guilherme Mapelli Chagas [Mestrando do PPGGEO - Programa de PósGraduação em Geografia da UFRRJ - Universidade Federal Rural do Rio de Janeiro], é um esforço de análise acerca de uma cidade-símbolo do novo desenvolvimentismo extemporâneo fluminense. Sede de um dos maiores e mais modernos complexos portuários da América Latina, como a fábrica de submarinos da Marinha do Brasil, Itaguaí assistiu nos últimos anos a conjugação da instalação de plantas fabris adjacentes ao porto com a intensificação de processos de reestruturação urbana, que envolvem desde inserções estéticas na cidade até a valorização da terra urbana em suas diversas formas.

9 Abrindo a seção "Trilhas de Pesquisa", Victor Arouca Gomes, mestrando do Programa de Pós-Graduação em Desenvolvimento Territorial e Políticas Públicas [PPGDT] da UFRRJ, apresenta "Maracanã Sustentável: Um estudo sobre a questão ambiental nos 
megaeventos esportivos". Neste texto, Victor Arouca avalia a utilização da "sustentabilidade ambiental" como estratégia de valorização do Estádio Jornalista Mario Filho (Maracanã), palco histórico e simbólico do futebol mundial. Visto como mercadoria a ser vendida, o Estádio do Maracanã - a rigor, a cidade do Rio de Janeiro e todo o Brasil - recebeu apetrechos que o tornaram "sustentável", como a reutilização de água nos banheiros e o uso de energia solar, sem incorporar as demandas sociais do entorno, marcado por remoções violentas em todo o processo de adequação ao padrão FIFA.

O artigo seguinte chama-se "Duque de Caxias-RJ: contradições entre crescimento econômico e desenvolvimento social"; escrito por Fernando Ribeiro Camaz, doutorando em Políticas Públicas e Formação Humana [PPFH / UERJ] e professor da Escola de Gestão \& Negócio / Universidade Petrobras, versa sobre o paradoxo de uma das cidades mais ricas do país - tomando como base o PIB resultante da força econômica da REDUC [Refinaria Duque de Caxias / Petrobrás] no município - apresentar índices sociais tão incongruentes. 0 desenvolvimento econômico, mais uma vez, não reverbera em qualidade de vida.

11 Por fim, "Ação política e afirmação territorial: turismo de base comunitária entre os caiçaras de São Gonçalo, Paraty, Rio de Janeiro", de Thiago Lammoglia Monteiro [Mestrando do PPGGEO - Programa de Pós-Graduação em Geografia da Universidade Federal Rural do Rio de Janeiro] trata do turismo de base comunitária entre os caiçaras na cidade de Paraty. Habitantes do litoral das regiões Sudeste e Sul do Brasil cujos meios de sobrevivências advêm de atividades tradicionais como pesca, caça e artesanato, os caiçaras encontram no ecoturismo uma possibilidade de afirmação territorial em meio a processos de intimidação e exclusão social.

12 Espaço e Economia: Revista Brasileira de Geografia Econômica mais uma vez busca contribuir para o debate crítico, atual e abrangente de temas que atravessam múltiplas escalas e realidades. Neste conturbado momento em que vemos a democracia brasileira em xeque e os ganhos sociais recentes - e ainda insuficientes - recebendo duras ameaças, é importante mostrar que há espaços capazes de manter viva a esperança.

\section{AUTOR}

\section{LEANDRO DIAS DE OLIVEIRA}

Doutor em Geografia pela UNICAMP - Universidade Estadual de Campinas, Mestre e Licenciado em Geografia pela UERJ - Universidade do Estado do Rio de Janeiro. Professor do Programa de Pós-Graduação em Geografia [PPGGEO / UFRRJ] e de Geografia Econômica e da Indústria do Departamento de Geociências da UFRRJ - Universidade Federal Rural do Rio de Janeiro. Coordenador do LAGEPPE - Laboratório de Geografia Econômica e Política e Práticas Educativas. Coordenador do PIBID [Programa Institucional de Bolsa de Iniciação à Docência] - Geografia UFRRJ. E-mails: ldiasufrrj@gmail.com / leandrodias@ufrrj.br 